\title{
A method evaluating stress intensity factors of mode I surface-cracks
}

\author{
Ma Youli \\ College of Energy and Civil \\ Engineering \\ Harbin University of Commerce \\ Harbin 150028, China \\ my10505@aliyun.com
}

\author{
Li Rongjuan \\ College of Energy and Civil \\ Engineering \\ Harbin University of Commerce \\ Harbin 150028, China \\ lirongjuanlrj@gmail.com
}

\author{
Pang Xinzhu \\ College of Petroleum Engineering \\ Harbin Institute of Petroleum \\ Harbin 150028, China \\ 944897112 @qq.com
}

\begin{abstract}
For mode I surface-cracks detected from structures, a method to evaluate stress intensity factors $K_{\text {est }}$ was suggested by measuring the opening displacement distributions along the crack and calculating stress distributions around it. The stress intensity factors of surface-cracks with different lengths subjecting various loading were evaluated by experiment. The stress intensity factors $K$ were also calculated using the traditional Newman-Raju's formula at the same conditions to demonstrate the effectiveness of this method. As a result, the values of $K_{\text {est }}$ and $K$ were good agreement for all cracks. That was to say, for surface-cracks detected from structures, the method suggested in this paper to evaluate stress intensity factors was efficacious even though the loading applied to the surface-cracks and the depth of it were unknown. So that remainder life of the structures could be evaluated.
\end{abstract}

Keywords-surface-cracks; structures; stress intensity factor; loading; opening displacement distributions

\section{INTRODUCTION}

During process of manufacture, installation and using of structures such as long-distance pipelines and bridges, the mechanical damage [1] or local corrosion [2, 3] of surface will be happened, which could be considered as surface-cracks. Evaluation of the remainder life of the structures became most important if surface-cracks was detected. For structures with surface-cracks, it was feasible to evaluate the remainder life by the stress intensity factor [4]. Hence, the study on method of evaluating stress intensity factor of surface-cracks had been going on for years $[5,6]$.

In past, the evaluation of the stress strength factor of surfacecracks required the load, the depth and the internal shape of the crack to be known [7]. However, the surface-cracks in structures was difficult to find when it worked.

So far, by measuring the opening displacement of crack, a method evaluating the stress distribution around it and the stress intensity factor were proposed for infinite plate with through crack [8]. On this basis, this method will be extended to longdistance oil and gas pipelines (As a limited board) [9]. In this study, by measuring opening displacement distribution along mode I surface-cracks and calculating stress distribution of it, an evaluation method of stress intensity factor of mode I surfacecracks was proposed. And the method was validated by experiment.

\section{CALCUlATION Formulation}

\section{A. Stress Distribuion along Surface-Cracks}

In Fig. 1, there was a surface-cracks with a length $2 a$ and a depth $c$. In direction of long axis of the plate (it's the $y$ direction and perpendicular to the crack), there was a uniform load $\sigma_{\mathrm{ap}}$. Then, opening displacement $V$ at any position of the crack could be expressed as (1),
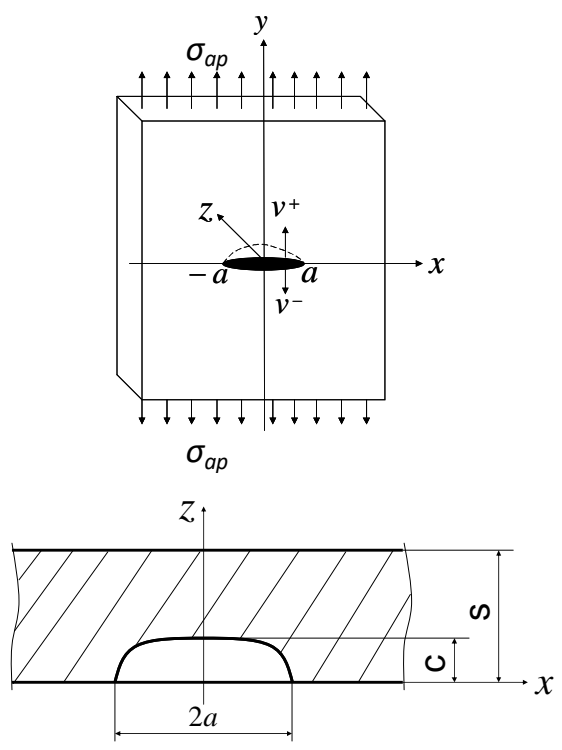

Fig. 1. Opening displacement of a surface-cracks in a finite plate.

$$
V=v^{+}-v^{-} \text {. }
$$


Here, $v^{+}$and $v^{-}$were opening displacement of the crack at $y>0$ and $y<0$, respectively. For surface-cracks in the finite plate, it was considered as a two-dimensional crack in the plane stress state, the measurement method of its opening displacement was given in section III. $C$. The relationship between the stress $\sigma_{\text {est }}(x)$ distribution along the crack and its opening displacement could be described as

$$
\sigma_{e s t}(x)=\frac{E}{4 \pi} \int_{-a}^{a} \frac{1}{t-x} \frac{d V}{d t} d t
$$

$E$ was coefficient of the material, and it was given as $206 \mathrm{GPa}$ in this study.

\section{B. Evaluation Method of Stess Intensity Factor}

Using the stress distribution along the crack in equation (2), the stress intensity factors $K_{\text {est }}$ at the crack or crack tip was calculated as

$$
K_{e s t}=\frac{1}{\sqrt{\pi a}} \int_{-a}^{a} \sigma_{e s t}(x) \sqrt{\frac{a+x}{a-x}} d x
$$

The opening displacement of surface-cracks specimens was measured in experiment, and it had already reflected the internal shape and effect of the internal opening displacement of the surface-cracks on it. Therefore, the stress intensity factor $K_{\text {est }}$ of the surface-cracks with depth and internal shape could be evaluated according it.

\section{EXPERIMENT RESULTS AND DISCUSSION}

\section{A. Experiment Specimens}

Experimental material was X45 steel, which was commonly used in petroleum pipeline, and its mechanical properties were shown in Table 1.

TABLE I. Mechanical Properties of The X45 PiPeline Material

\begin{tabular}{|c|c|c|c|c|}
\hline $\begin{array}{c}\text { Poisson } \\
\text { ratio } \\
/ \mathbf{v}\end{array}$ & $\begin{array}{c}\text { Yield } \\
\text { strength } \\
\text { /MPa }\end{array}$ & $\begin{array}{c}\text { Tensile } \\
\text { strength } \\
/ \mathbf{M P a}\end{array}$ & $\begin{array}{c}\text { Elongation } \\
/ \%\end{array}$ & $\begin{array}{c}\text { Section } \\
\text { shrinkage } \\
/ \%\end{array}$ \\
\hline 0.3 & 332 & 620 & 22.4 & 31.2 \\
\hline
\end{tabular}

In this experiment, the rectangular specimen was shown in Fig. 2. In order to obtain the surface-cracks at a predetermined location, a non-penetrating hole with diameter $\phi=1.0 \mathrm{~mm}$ and depth $1.0 \mathrm{~mm}$ was opened in center of specimen. Then, the surface of the center specimen was grinding bright for the convenience of observation in process of experiment. In order to eliminate the influence of mechanical machining on the local stress produced in the specimen, the specimen was treated with annealing. Its heat treatment temperature was $600{ }^{\circ} \mathrm{C}$, and time was kept in 1 hour.
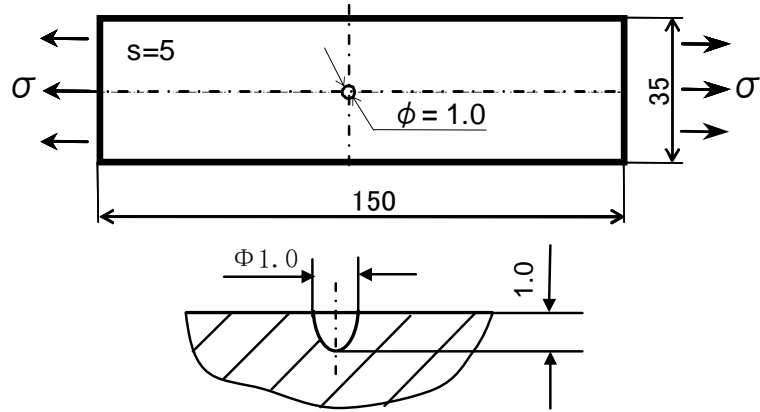

Fig. 2. Specimen with a hole in the center.

\section{B. Fatigue Experiment}

Cyclic loading was applied to the long axis direction of the specimen in Fig. 2, the surface-cracks were made at the center of the specimen surface.

Fatigue experimental conditions were as follows: the fatigue test was carried out on a pulsed fatigue test machine with a sine wave load, a load frequency of $20 \mathrm{~Hz}$, a stress ratio(ratio of minimum stress to maximum stress) $R=0$, maximum stress value $\sigma_{\max }=120 \mathrm{MPa}$, until the one-sided crack length $a=2.05,3.02$ and $4.10 \mathrm{~mm}$ end of fatigue experiment. In this experiment, three specimens with different lengths of mode I surface-cracks were fabricated.

In order to eliminate residual stress around the crack, the test specimen was subjected to an annealing heat treatment again, and the conditions were same as before the crack production.

After annealing, a stress determination by $\mathrm{x}$-ray with irradiated area $1 \times 1 \mathrm{~mm}^{2}$ which was used to measure the compressive residual stress along the surface-cracks [10]. The measurement results of the residual stress $\sigma_{\mathrm{r}}$ around the surfacecracks $a=4.10 \mathrm{~mm}$ after heat treatment were shown in Fig. 3, and the $x$ axis was the distance from center of the crack.

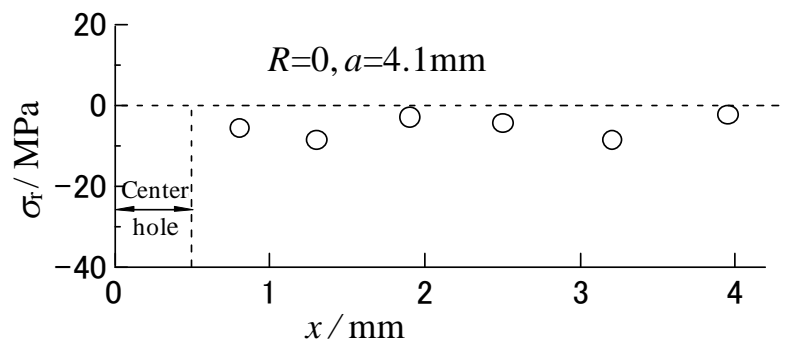

Fig. 3. Residual stress distributions around annealed crack.

From the experiment, we known the residual stress from the center to the crack tip was close to zero after heat treatment. Therefore, the effect of the residual stress around the crack on the crack displacement characteristics could be neglected. 


\section{Measurement of Crack Opening Displacement}

The opening displacement distribution along the crack was measured by an optical microscope with a magnification of 100 times. In Fig. 4(a), micro-indentation was printed with distance $50 \mu \mathrm{m}$, and showed symmetrical distribution along the crack with distance $60 \mu \mathrm{m}$ (it could be considered as a pair of indentation). The distances of each pair of indentation were $y$ and $y_{0}=60$ under load and no-load, respectively. Therefore, the difference between $y$ and $y_{0}$ was given as $V=y-y_{0}$, and it was the value of displacement at the point where the crack opening direction was under the load. Then, the values of opening displacement distribution along surface-cracks were obtained by performing the above operations on each pair of indentations.

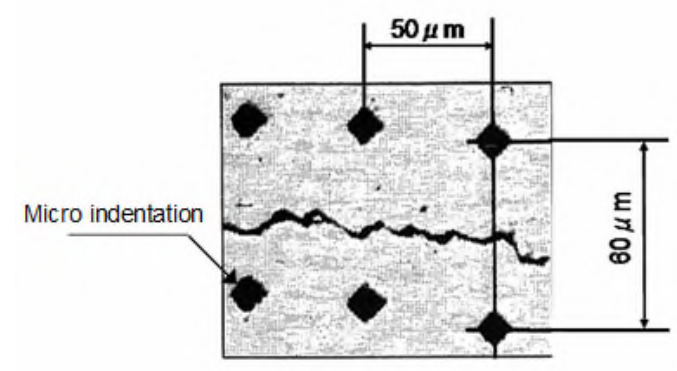

(a) Before loading

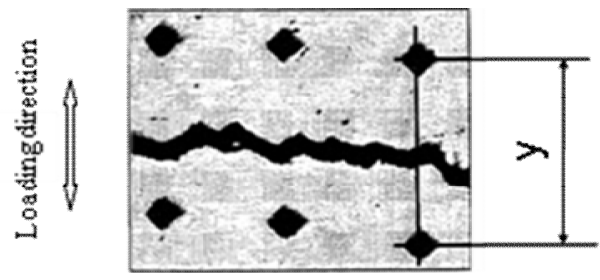

(b) After loading

Fig. 4. Measurement method of crack opening displacement distributions

For specimens with unilateral crack length $a=4.10 \mathrm{~mm}$, a constant load was applied in longitudinal direction (that is, in the direction perpendicular to the crack). The measurement values $V$ of the displacement along the crack under the loads $\sigma_{\mathrm{ap}}=100,125$ and $150 \mathrm{MPa}$ were calculated and shown in Fig. 5. The dashed line represented the approximate values of the crack opening displacement and it was calculated as [10]

$$
V(x)=\frac{A}{a} \sqrt{a^{2}-x^{2}}\left(B x^{4}+C x^{2}+D\right) .
$$

In (4), $A, B, C$ and $D$ were coefficient.

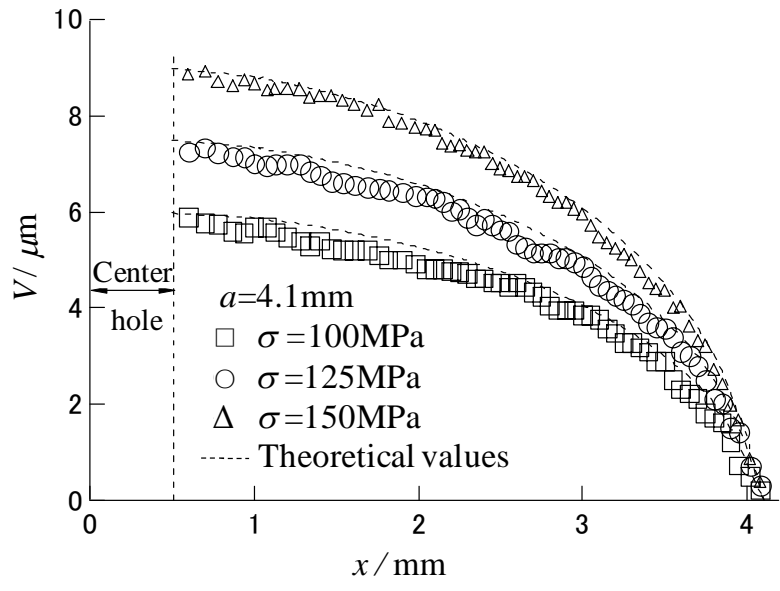

Fig. 5. Crack opening displacement distributions measured along surface-cracks

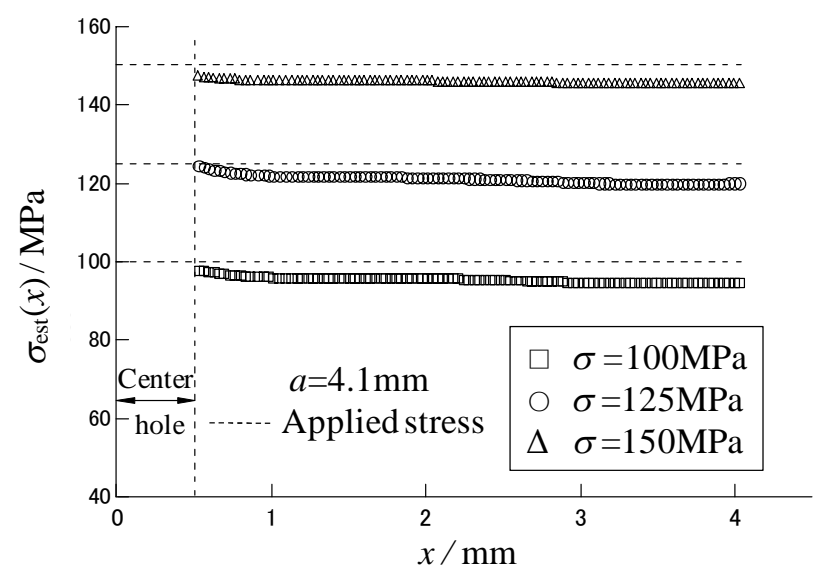

Fig. 6. Stress distribution along surface cracks.

\section{Stress Distribution along Crack}

The measurement results of the opening displacement along the crack in Fig. 5 were substituted into (2). Then, the values of stress distribution $\sigma_{\text {est }}(x)$ along the crack were obtained, and shown in Fig. 6. The results showed that the experiment stress distribution along the crack was slightly lower than that of the stress applied to the specimen. It might be the reason that the depth of the surface-cracks or the irregular shape of the internal crack impacted on the values of experiment.

\section{E. Surface-Cracks Stress Intensity Factors}

For the surface-cracks specimens with length $a=2.05,3.02$ and $4.10 \mathrm{~mm}$ subjecting load of $\sigma_{\mathrm{ap}}=60,80,100,125,150$ and $160 \mathrm{MPa}$, the values of stress distribution $\sigma_{\mathrm{est}}(x)$ along the crack were calculated by measuring the opening displacement. The results were substituted into (3), these surface-cracks stress intensity factor were evaluated. In order to compare the evaluation results, the stress intensity factor of the above 
specimens under various load was calculated using Newman-Raju formula [11], which was shown in (5).

$$
K=F \sigma_{a p} \sqrt{\pi \frac{c}{Q}} .
$$

Here, $\sigma_{\mathrm{ap}} \longrightarrow$ Load applied to specimen MPa,

$c$ Crack depth $\mathrm{m}$,

$\mathrm{F}, \mathrm{Q}-$ Correction coefficient.

The results were written as $K$. The relationship of $K_{\text {est }}$ and $K$ (the ratio of crack depth to length: $c / a=0.6$ ) was shown in Fig. 7.

In Fig. 7, the results of surface-cracks stress intensity factor with different length in various loading by using an evaluation method proposed in this paper and Newman-Raju formula were basically same. Therefore, even though the load and the surfacecracks depth were unknown, the stress intensity factor of surfacecracks could be correctly evaluated by measuring the opening displacement along the crack. That was to say, if the crack of structural parts was found in service period, the method proposed in this paper could be used to evaluate the remainder strength of it.

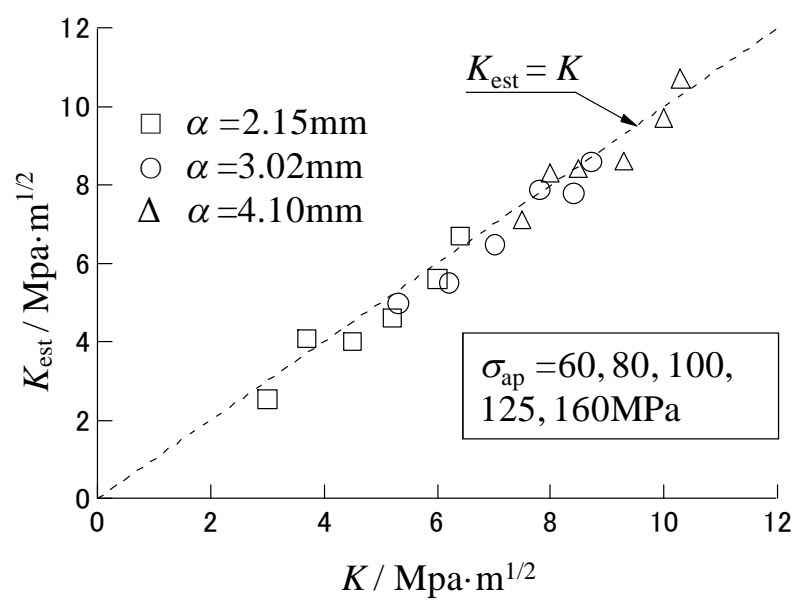

Fig. 7. Relationship between stress intensity factors $K_{\text {est }}$ and $K$ for surface-cracks

\section{CONCLUSION}

It was normal that the partial defect (surface-cracks) of engineering structures was detected during work time. Therefore, how to evaluate the remainder life of structures became the important problem in industry. It was also investigated in this paper, and the conclusions were given as follows:

1). Based on the investigation of through cracks, an evaluation method of stress intensity factor of mode I surfacecracks was proposed. By measuring the opening displacement distribution of mode I surface-cracks, the stress distribution along the crack was calculated at first. Then, the stress intensity factor could be evaluated at the end of the crack.

2 ). The stress intensity factor $K_{\text {est }}$ and $K$ of surface-cracks with different lengths subjecting various loading were evaluated by experiment and Newman-Raju formula, respectively. The results of $K_{\text {est }}$ and $K$ were basically same. It could be proved that a evaluating method of the stress intensity factor proposed in this study was reliability and validity.

Therefore, for mode I surface-cracks in structural parts during service period, even if the load and the surface-cracks depth were unknown, the stress intensity factor of surface-cracks could be evaluated using a evaluating method proposed in this study. Furthermore, the safety of the structural parts in working also could be evaluated.

\section{REFERENCES}

[1] Z. Zhao, Q. Zhang, B. Feng, "Research Advance of Perfect about Mechanical Damage of Oil and Gas pipelines", Oil \& Gas Storage Transport., vol. 31(4), pp. 241-245, 2012.

[2] Y. Wang, Z. Xiao, "Safety evaluation standards for in-service oil and gas pipelines with defects", Oil \& Gas Storage Transport. vol. 32(6), pp. 587589, 2013.

[3] Y. Wang, Z. Xiao, "Safety Evaluation Standards for In-service Oil and Gas Pipelines with Defects", Oil \& Gas Storage Transport. vol. 32(6), pp. 587 $589,2013$.

[4] L. Yang, Y. Hao, C. Ma, et al., "Influence of Heat Treatment on Low Cycle Fatigue Behavior of Extruded 6061 Aluminum Alloy", J. Shenyang Univ. Tech. vol. 32(5), pp. 496-500, 2010.

[5] X. Gu, Z. Wu, "New Empirical Stress-intensity Factor Equations for Surface Cracks", Eng. Mech. vol. 25(7), pp. 35-39, 2008.

[6] G. Li, L. Hao, J. Li, "An Expression of Stress Intensity Factor in Sucker Rod String with Surface Crack”, Oil Field Equip. vol. 36(12), pp. 14-16, 2007.

[7] J. Zhou, Y. Jiang, "Protection Process about the Accident Causing from Mechanic Defect in Oil-gas Pipe-line”, Oil \& Gas Storage Transport. vol. 31(2), pp. 86-91, 2012.

[8] Y. Ma, "Evaluating Stress Distributions and Stress Intensity Factors of a Crack under Mixed-mode Conditions in Aluminum Alloy", 2010 International Conference on Measuring Technology and Mechatronics Automation, Feb. 2010, pp. 164-167.

[9] Y. Ma, "Initial Fracture Behavior and Influencing Factors of Fatigue Cracks in an Oil-gas Pipeline”, J. Harbin Eng. Univ. vol. 33(8), pp. 984 988, 2012.

[10] Y. Ma, "Study on Fatigue Crack Propagation Behavior under Mixed-Mode Conditions with Compressive Residual Stress", Tokyo: Parliament Library, 2006.

[11] J.C. Newman, I.S. Raju, “An Empirical Stress-intensity Factor Equation for the Surface Crack, Eng. Fract. Mech. vol. 15(1), pp. 185-192, 1981. 